\title{
Equidad y respuesta del Sistema Nacional de Salud de Cuba ante la COVID-19
}

\author{
Pedro Mas Bermejo ${ }^{1}$, Lizet Sánchez Valdés², Lorenzo Somarriba López ${ }^{3}$, Nelly Cristina Valdivia \\ Onega 4 , María Josefina Vidal Ledo ${ }^{5}$, Ileana Alfonso Sánchez ${ }^{6}$, Armando Seuc Jo7, Yudivian Almeida \\ $\mathrm{Cruz}^{8}$ y Roberto Morales Ojeda ${ }^{8}$
}

Forma de citar

Mas Bermejo P, Sánchez Valdés L, Somarriba López L, Valdivia Onega NC, Vidal Ledo MJ, Alfonso Sánchez I, et al. Equidad y respuesta del Sistema Nacional de Salud de Cuba ante la COVID-19. Rev Panam Salud Publica. 2020;44:e138. https://doi. org/10.26633/RPSP.2020.138

RESUMEN El Sistema Nacional de Salud de Cuba ha logrado garantizar una respuesta eficaz y con equidad en el enfren-
tamiento a la COVID-19. La cobertura de salud universal y gratuita, basada en la atención primaria, sigue el
principio de equidad, por lo que los mayores recursos se asignan a los territorios del estrato socioeconómico
más bajo, que concentra mayores riesgos de salud, seguidos de los de estratos medio y alto, en ese orden.
Esto permitió tener tasas de letalidad similares en los tres estratos, y a nivel nacional la de Cuba es una de las
tasas más bajas de la Región de las Américas. Antes de identificar el primer caso en Cuba, se elaboró el Plan
para la Prevención y Control del Coronavirus, con participación multisectorial, y al confirmarse el primer caso
se creó el Grupo Temporal de Trabajo para Enfrentar la COVID-19 como órgano asesor del Gobierno. Las
acciones de enfrentamiento a la pandemia comienzan en la comunidad con medidas preventivas, continúan
en los centros de aislamiento y terminan nuevamente en la comunidad, con acciones de vigilancia y acom-
pañamiento a los enfermos recuperados. Siguiendo el principio de territorialidad, se crearon laboratorios de
diagnóstico molecular en las provincias que no lo tenían. La atención médica y los tratamientos gratuitos; la
preparación de un plan de gobierno intersectorial nacional único; la utilización de estrategias particulares
para la pesquisa, diagnóstico y rastreo de casos; y la implementación de un protocolo universal para la pre-
vención de la enfermedad y el tratamiento de los casos confirmados permitieron el control de la enfermedad
con una perspectiva de equidad en salud.

Palabras claves Infecciones por coronavirus; equidad en salud; cobertura universal de salud; atención primaria de salud; Cuba.

El concepto de equidad viene de larga data y es complejo, por lo que a lo largo del tiempo ha tenido diversas definiciones. El término, derivado del latín aequĭtas, alude a la igualdad de ánimo (1). Alcanzar la equidad en la salud significa, en el momento actual, que las personas puedan desarrollar su máximo potencial de salud independientemente de su posición social u otras circunstancias determinadas por factores sociales.
La equidad en la salud implica que los recursos se asignen según la necesidad y la justicia de los procesos, y se evite la discriminación en la prestación de la asistencia sanitaria $(2,3)$.

La pandemia de la COVID-19, enfermedad causada por el coronavirus denominado SARS CoV-2, ha generado hasta el $1 .^{\circ}$ de octubre del 2020 más de 34 millones de casos confirmados y de 1 millón de fallecidos, con una tasa de letalidad (número

\footnotetext{
1 Instituto de Medicina Tropical Pedro Kouri, La Habana, Cuba. $\square$ Pedro Mas Bermejo, pmasbe@infomed.sld.cu

2 Centro de Inmunología Molecular, La Habana, Cuba.

3 Ministerio de Salud Pública, La Habana, Cuba.

4 Centro Internacional de Salud La Pradera, La Habana, Cuba.
} 
de fallecidos del total de positivos acumulados) estimada de 2,98\%. En la región de las Américas se han notificado más de 16 millones de casos confirmados y más de 560000 fallecidos, para una letalidad de 3,33\%; todo esto ha puesto a prueba la capacidad de los sistemas de salud pública en el mundo (4).

Esta pandemia requiere de una adecuada infraestructura hospitalaria y de laboratorio, además de sistemas de salud capaces de llevar a cabo el rastreo de los contactos de los casos confirmados y suficientes personal de salud y equipamiento para brindar atención a una gran cantidad de pacientes al mismo tiempo. Por otra parte, tal como ocurre con otras enfermedades infecciosas, las inequidades incrementan tanto la transmisión de la COVID-19 como el nivel de gravedad con el que transita la enfermedad al interior de las sociedades más pobres (5). Así, las consecuencias de la enfermedad recaen de forma desproporcionada en los grupos que se encuentran en una situación de vulnerabilidad y en los que sufren de discriminación. Basado en esto, la Organización Panamericana de la Salud (OPS) ha hecho un llamado a los países de la Región a considerar la perspectiva de la equidad, el género, las características étnicas y los derechos humanos en sus respuestas a la COVID-19 (6).

Para Cuba, la equidad, la promoción del desarrollo social y humano, y la justicia social son pilares básicos en la concepción de su política social (7) asentados en la Constitución de la República, en la que se enfatiza que “...la salud pública es un derecho de todas las personas y es responsabilidad del estado garantizar el acceso, la gratuidad y la calidad de los servicios de atención, protección y recuperación" (8).

En correspondencia con la actualización del modelo económico cubano, las transformaciones en el sector de la salud han permitido redefinir funciones y reclasificar las estructuras en todos los niveles de atención en el país $(9,10)$. Esto ha permitido contar con una organización de los servicios favorable para el enfrentamiento de situaciones extraordinarias y de desastres, y se ha comprobado su eficacia en el caso particular de la pandemia de la COVID-19.

Hasta el $1 .^{\circ}$ de octubre del 2020 se habían confirmado en Cuba 5670 casos. De ellos 5078 ya se habían recuperado, 518 se encontraban aún hospitalizados y se lamentaba el fallecimiento de 122 personas positivas al SARS-CoV-2, para una tasa de letalidad de 2,15, una de las más bajas de América Latina (4).

El presente trabajo tiene como objetivo mostrar cómo el Sistema Nacional de Salud (SNS) de Cuba logró garantizar una respuesta eficaz y con equidad en el enfrentamiento a la COVID-19.

\section{EQUIDAD DEL SISTEMA DE SALUD BASADO EN LA ATENCIÓN PRIMARIA}

La organización del SNS cubano asume la equidad como una premisa para garantizar la salud de la población con eficacia y satisfacción social, bajo los principios de accesibilidad y gratuidad de los servicios, con orientación preventiva, elevada participación comunitaria e intersectorialidad. Este es un sistema centralizado a nivel normativo y en el orden metodológico, pero descentralizado en la ejecución de sus programas y acciones, en los que se aplican los adelantos de la ciencia y la técnica; además, se brinda colaboración internacional a países que lo requieran y lo soliciten (11).

La cobertura universal del SNS se fundamenta en la estrategia de atención primaria de salud (APS) y se basa en un modelo público, único e integrado en redes de prestación de servicios por niveles de atención, y en políticas y programas enfocados en la epidemiología, la salud ambiental y la atención médica. En esta red se coordinan acciones y se cumplen las funciones de la salud pública a partir de los determinantes del estado de salud de la población. Tanto dentro del sector como a nivel social se enfatiza en la promoción de la salud y la prevención, bajo el principio de intersectorialidad (12).

Otra fortaleza del SNS es su base programática, que permite disponer de procedimientos para conducir a los pacientes de manera asistida y regionalizada a través de la red de servicios. Se cuenta con 479623 trabajadores sanitarios distribuidos en tres niveles de atención -interconectados mediante el sistema de referencias y contrarreferencias-, centrados en el médico de familia, que acompaña al paciente en su paso por toda la red con una permanente actualización (13).

Así, al sistema primario de atención basado en consultorios comunitarios de medicina familiar se unen 150 hospitales municipales que disponen de todas las especialidades - y conforman el segundo nivel de atención-y cuentan con 110 salas de terapia intensiva hospitalaria. El tercer nivel de atención está compuesto por 12 institutos especializados y de investigación con funciones asistenciales. Todos los ciudadanos tienen acceso gratuito a todas las instancias de salud, desde las de atención primaria hasta las de mayor grado de especialización en el nivel terciario de atención. Este conjunto de instituciones funciona como parte de un proceso de regionalización de los servicios en general, desde el punto de vista de la atención geográfica y de las especialidades, lo cual es expresión de la equidad en el acceso y las oportunidades (13)

El modelo cubano de medicina familiar incluye, entre sus procesos clave, la dispensarización y el análisis de la situación de salud, lo que permite identificar a los individuos y a las familias en condición de vulnerabilidad. Lo más trascendente de esto es la capacidad de definir las necesidades de recursos en función de mejorar el estado de salud de la comunidad. Por su autoridad y relación con los líderes del gobierno local y de las organizaciones comunitarias, el médico y el enfermero de la familia disponen de herramientas para modificar conductas e incidir en la percepción de riesgo de la población que atienden.

No obstante, existen particularidades socioeconómicas y culturales al interior del país que provocan diferencias territoriales en las condiciones de vida. En estudios previos (14), las 15 provincias de Cuba y el municipio especial Isla de la Juventud se clasificaron según el índice de condiciones de vida en tres estratos: bajo $(<0,40)$, medio (de 0,41 a 0,55$)$ y alto $(>0,55)$. De esta forma, las provincias orientales del país (Las Tunas, Holguín, Granma, Santiago de Cuba y Guantánamo) se ubican en el estrato bajo, mientras algunas provincias del occidente y el centro (Pinar del Río, Mayabeque, Matanzas, Villa Clara y Sancti Spíritus) se ubican en el estrato medio y las otras (Artemisa, La Habana, Cienfuegos, Ciego de Ávila, Camagüey y el municipio especial Isla de la Juventud) están en el estrato alto.

El SNS mantiene un perfeccionamiento continuo de sus recursos humanos y sus servicios, lo que le ha permitido mejorar de manera sostenida los principales indicadores sanitarios y del estado de salud de la población (15). Consecuentes con el principio de equidad, los mayores recursos humanos y materiales se asignan a los territorios del estrato más bajo, que concentra los mayores riesgos de salud, seguidos de los de los estratos medio y alto, en ese orden (cuadro 1), aunque, como se puede 
CUADRO 1. Estadísticas nacionales relacionadas con la COVID-19 por estratos, Cuba, $1 .^{\circ}$ de octubre del 2020

\begin{tabular}{|c|c|c|c|c|c|c|c|}
\hline Estrato $^{\mathrm{a}}$ & Población & $\begin{array}{c}\text { Médicos por } \\
100000 \text { habitantes }\end{array}$ & Pruebas realizadas $^{b}$ & Casos confirmados & $\begin{array}{l}\text { Contactos } \\
\text { estudiados }\end{array}$ & $\begin{array}{l}\text { Contactos positivos } \\
\text { a la COVID-19t }\end{array}$ & $\begin{array}{l}\text { Fallecidos positivos } \\
\text { a la COVID-19 }\end{array}$ \\
\hline Alto ${ }^{C}$ & 4335512 & 71,2 & 478106 & 4603 & 72660 & 5,4 & 88 \\
\hline Medio $^{d}$ & 2928959 & 75,9 & 83295 & 761 & 18600 & 4,3 & 24 \\
\hline
\end{tabular}

Fuente: Elaborado por los autores.

astratos según el índice de condiciones de vida: bajo < 0,40; medio de 0,41 a 0,55; y alto >0,55 (14).

¿ Prueba de la reacción en cadena de la polimerasa (PCR) en tiempo real.

c Provincias Artemisa, La Habana, Cienfuegos, Ciego de Avila y Camagüey y el municipio especial Isla de la Juventud.

Provincias Pinar del Río, Mayabeque, Matanzas, Villa Clara y Sancti Spíritus.

Promedio por caso confirmado.

observar, la trasmisión de la enfermedad afectó mayormente al estrato alto, que incluye la capital del país.

\section{PREPARACIÓN PARA EL ENFRENTAMIENTO A LA COVID-19 EN CUBA}

En enero del 2020, el Gobierno cubano, de conjunto con el Ministerio de Salud Pública y con la participación de todos los sectores económicos y sociales involucrados, activó el Grupo Temporal Nacional para enfrentar la COVID-19 y comenzó el despliegue de la gestión gubernamental orientada a movilizar las importantes capacidades científicas, tecnológicas y profesionales para enfrentar la pandemia, que se recogen en el Plan para la Prevención y Control del Coronavirus (16). Este plan define las políticas de gobierno, comunicación, y ciencia y tecnología cuidando de garantizar la equidad de las acciones de salud pública en la aplicación de las estrategias de enfrentamiento; además, establece la preparación de los recursos humanos y materiales que acompañan la implementación y los ajustes necesarios para vencer este desafío (17).

Al aparecer en marzo los primeros casos importados, se implementaron las decisiones y planes de acción en cada sector económico, que incluyó la activación en todos los territorios del país de los consejos de defensa (estructura a nivel nacional, provincial y municipal, con un enfoque intersectorial, para conciliar estrategias y acciones ante desastres naturales, epidemias y otros eventos extraordinarios que afecten a la comunidad). Los consejos de defensa coordinan y controlan las misiones y acciones en cada entidad y comunidad para reforzar la promoción de la salud (información, educación y comunicación), las medidas de distanciamiento social, el control de las fronteras y la modificación de los factores de riesgo, así como la protección de las poblaciones más vulnerables (18).

El 20 de marzo, nueve días después de haberse detectado los tres primeros casos importados, procedentes de Europa, el Gobierno anunció nuevas medidas para enfrentar la COVID19 y se activó el Grupo Técnico Temporal de Trabajo para Enfrentar la COVID-19, integrado por expertos —académicos y especialistas de universidades, centros de investigación y servicios asistenciales-, con la misión de asesorar y colaborar con el primer nivel de dirección del Estado para la identificación de la magnitud y la diseminación de la enfermedad en el país, su riesgo y su severidad. Este grupo aportó criterios para la evaluación de las intervenciones, la planificación de recursos y el análisis de la situación epidemiológica en Cuba y en el contexto internacional. Además, colaboró en el análisis y la propuesta de las medidas para el enfrentamiento de la enfermedad, la modelación de escenarios y la creación de un tablero interactivo para el seguimiento y el control de la epidemia (19-21).

Con el objetivo de lograr el acceso equitativo a toda la información relacionada con la situación epidemiológica, se estableció un sistema de comunicación a la población con información debidamente actualizada. Desde el 11 de marzo, día en que se detectaron los primeros casos importados, los medios masivos y las redes sociales difunden diariamente la conferencia de actualización que ofrece el director nacional de epidemiología del Ministerio de Salud Pública y sesiones televisivas en horario estelar, como el programa Mesa Redonda, con la participación del ministro y otros funcionarios del Ministerio de Salud Pública, científicos y altos funcionarios del Gobierno y el Estado (22).

\section{PESQUISA ACTIVA, DIAGNÓSTICO, RASTREO Y AISLAMIENTO DE CASOS}

La pesquisa activa ha estado a cargo de los miembros de los equipos básicos de salud- una estructura del nivel primario de atención, compuestos por médicos, enfermeros y especialistas-, que se reforzaron con profesores y alumnos de las universidades de ciencias médicas del país como parte de sus actividades habituales de formación y educación en el trabajo. Este contacto sistemático y permanente con la comunidad permitió la detección temprana y oportuna de los casos positivos, ya fueran asintomáticos o presentaran síntomas, así como el seguimiento de la cadena epidemiológica de transmisión. Se fortaleció el funcionamiento del nivel primario de atención -integrado al resto del sistema- con la capacitación y la preparación de los recursos humanos, lo que permitió actuar con inmediatez, incorporar habilidades para la investigación epidemiológica en la identificación de contactos directos y de personas vulnerables, elevar la capacidad de motivación e incorporación a la comunidad como sujeto de las acciones, y gestionar el funcionamiento de los servicios. Estos fueron elementos clave para lograr la eficacia social y la satisfacción de la población aun en tan compleja situación.

La prueba de la reacción en cadena de la polimerasa (PCR) en tiempo real constituye el elemento esencial confirmatorio de caso. El número de estas pruebas se incrementó en la medida en que evolucionó la epidemia, con una distribución relativamente uniforme en la mayoría de las regiones; la mayor diferencia ocurrió en la capital, que desde los inicios se convirtió en el epicentro de la epidemia en el país (figura 1).

Inicialmente se contó con tres laboratorios destinados a la realización de pruebas de PCR en tiempo real, uno por cada región 
FIGURA 1. Distribución de los casos confirmados de la COVID-19 y número de pruebas por $\mathrm{PCR}^{\mathrm{a}}$ realizadas, según el estrato ${ }^{\mathrm{b}}$ y el índice de condiciones de vida en Cuba, $1^{\circ}$ de octubre de 2020

La Habana
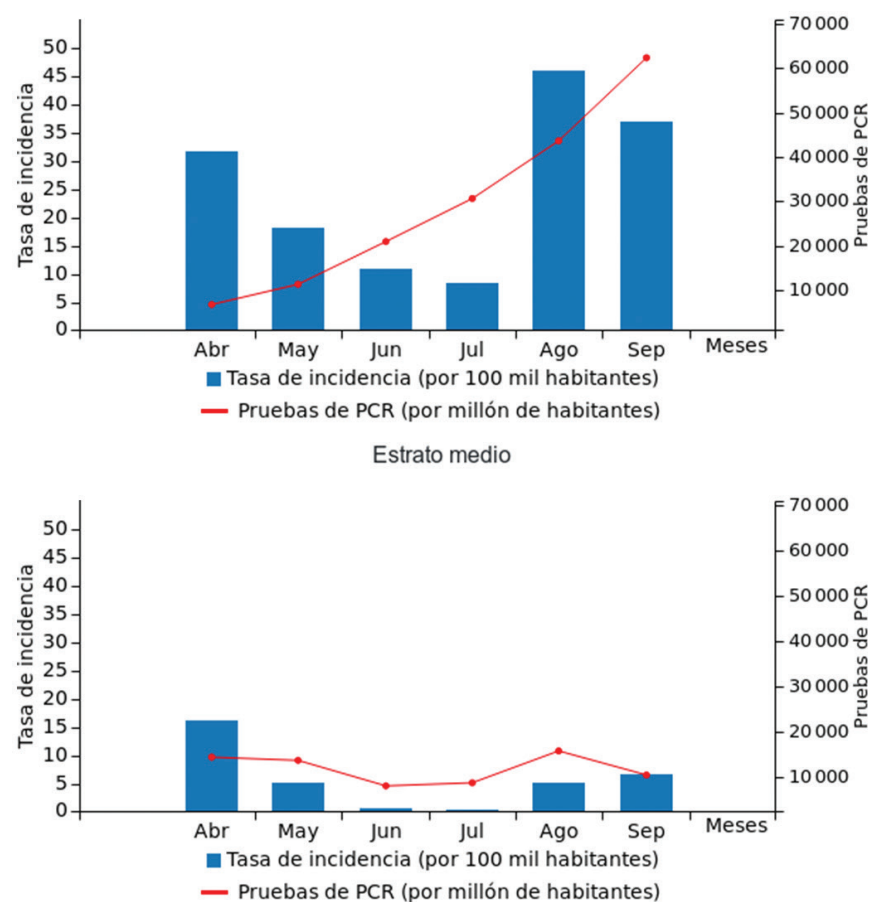

Estrato alto (excluyendo La Habana)
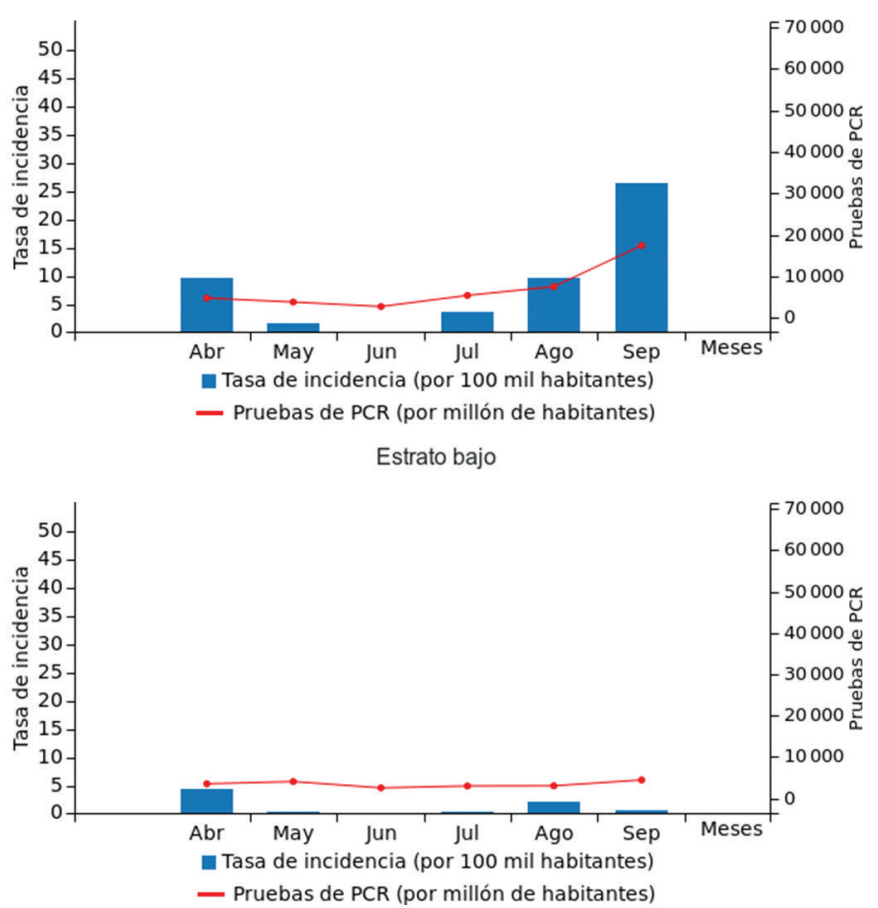

Fuente: Elaborado por los autores sobre la base de datos tomados de: https:Itcovid19cubadata.github.iof\#cuba a PCR: Prueba de reacción en cadena de la polimerasa en tiempo real.

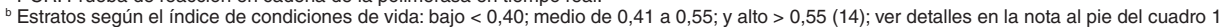

del país: en La Habana se procesaban las muestras recogidas en el occidente (provincias de Pinar del Río, Artemisa, Mayabeque, La Habana y Matanzas, y el municipio especial Isla de la Juventud), en Villa Clara las del centro (Villa Clara, Cienfuegos, Sancti Spíritus, Ciego de Ávila y Camagüey) y en Santiago de Cuba las procedentes de las provincias orientales (Las Tunas, Holguín, Granma, Santiago de Cuba y Guantánamo). Posteriormente, se fueron incorporando otros laboratorios en La Habana, debido a la compleja situación epidemiológica en la región occidental y se puso en práctica una estrategia de desarrollo de la red de diagnóstico del país para cumplir el objetivo de contar con un laboratorio de biología molecular en cada provincia. En los laboratorios que ya existían se incrementó la jornada laboral a 24 horas, con turnos laborales rotativos, se mejoró el equipamiento y se aumentó la capacidad de diagnóstico con el entrenamiento del personal. Esto permitió que en cada provincia se pudiera realizar el número de pruebas requeridas de acuerdo con la situación epidemiológica. Entre el 11 de marzo y el 30 de septiembre de 2020 se habían analizado 621180 muestras (55 410 pruebas por millón de habitantes).

En todo el país se identificaron y aislaron los contactos de primer y segundo órdenes de cada caso confirmado. A todos se les realizaron las pruebas correspondientes para determinar la posible infección por el SARS-CoV-2. Como un aporte intersectorial ante la situación creada, en todas las provincias y el municipio especial Isla de la Juventud se habilitaron nuevas facilidades de atención sanitaria fuera de las instalaciones del sistema de salud: 1103 camas en centros de atención a casos sospechosos de menor riesgo, 3636 camas en centros de vigilancia para contactos de casos diagnosticados y 4039 camas en centros de vigilancia para viajeros. Se consideró caso sospechoso a toda persona que presentara alguna manifestación clínica sugestiva de COVID-19, como fiebre, tos seca, disnea gradual u otra manifestación respiratoria, decaimiento, malestar general, cefalea, diarreas, o pérdida del olfato o el gusto. De esta manera, se desplegó una infraestructura adicional en los servicios que impidió que colapsara el sistema de salud (22).

Además, con el propósito de estudiar la dispersión de la enfermedad en el país, se realizó una encuesta de seroprevalencia que involucró a todas las provincias, incluidos los municipios que hasta ese momento no habían notificado casos positivos. Este estudio, desarrollado en cuatro etapas y que se encuentra aún en ejecución, está basado en una muestra representativa de la población con aproximadamente 4000 personas y 1400 hogares.

\section{PREVENCIÓN DE LA INFECCIÓN Y ATENCIÓN A PACIENTES CONFIRMADOS}

Los pacientes confirmados se hospitalizaron hasta resultar negativos a la prueba de la COVID-19 por PCR en tiempo real y pasaron luego a una cuarentena de 14 días en su hogar, bajo la vigilancia del médico de familia. A todos se les brindó tratamiento según el protocolo adoptado en Cuba para el enfrentamiento de la enfermedad (23). Este protocolo es único y tiene carácter normativo y alcance nacional, es decir, se aplica 
en todas las instituciones sanitarias del país en todos los niveles de atención. No obstante, es flexible para que se pueda adaptar según el estado clínico de cada paciente y su evolución, y se actualiza sistemáticamente según las nuevas evidencias científicas sobre el SARS-CoV-2 y la COVID-19 que surgen en Cuba y el mundo.

El protocolo cubano establece como prioridades la prevención de la infección, el control de la enfermedad y el mejor manejo de los casos, así como la protección de los trabajadores de la salud y la población. Como se muestra en la figura 2, las acciones de enfrentamiento a la pandemia en Cuba comienzan en la comunidad con medidas preventivas, continúan en los centros de aislamiento de casos sospechosos, contactos de personas confirmadas y sospechosas, y viajeros que arriban al país y terminan nuevamente en la comunidad, con las acciones de vigilancia y acompañamiento a los enfermos recuperados.

La búsqueda activa, casa por casa, de casos sospechosos y la realización de pruebas a todos los contactos de los casos han sido características singulares de la estrategia cubana frente a la epidemia. Esto ha garantizado una atención más oportuna, antes de que aparezcan complicaciones. Los grupos con mayor riesgo en la población cubana coinciden con lo informado en la literatura internacional: personas residentes en instituciones, mayores de 60 años y menores de 60 años con enfermedades crónicas, las más frecuentes de ellas son la hipertensión arterial, la diabetes mellitus, la cardiopatía isquémica, la enfermedad pulmonar obstructiva crónica y la insuficiencia renal crónica (24).

Desde el inicio de la pandemia hasta el $10^{\circ}$ de octubre, se habían detectado en el país 625 casos de COVID-19 menores de 18 años. La tasa de incidencia específica por edades aumentó significativamente de 22,4 por 100000 menores de 1 año hasta 33,19 por 100000 adolescentes de 15 a 18 años $(p=0,02)$. Aunque resulta mayor que la informada internacionalmente (25), en la mayoría de los niños la enfermedad cursó sin complicaciones o de manera asintomática. El elevado número de casos detectados en edades pediátricas en Cuba puede deberse a la amplia pesquisa desarrollada en el país y a la prioridad dada por el SNS al Programa de Atención Materno Infantil. Así, en Cuba se instauró un sistema de vigilancia para elevar la percepción de riesgo y el diagnóstico precoz de síndromes inflamatorios multisistémicos y la enfermedad de Kawasaki; este sistema permitió detectar dos niños con estas complicaciones, que fueron atendidos oportunamente y se recuperaron.

Los tratamientos de todos los pacientes diagnosticados están disponibles libre de costo en todas las instituciones de salud del país, y los fármacos empleados son en su mayoría (14 de los 18 productos principales utilizados) de producción nacional; la industria biotecnológica cubana ha sido la responsable de garantizar la accesibilidad de todos los productos contemplados en el protocolo cubano, incluidas terapias innovadoras eficaces para prevenir el paso de los pacientes a formas graves de la enfermedad (26-30).

\section{PRINCIPALES RESULTADOSY SITUACIÓN ACTUAL}

Las acciones del Gobierno cubano se emprendieron desde el comienzo con un enfoque intersectorial dirigido fundamentalmente a mitigar los efectos de la enfermedad e interrumpir la transmisión de la COVID-19. Todas las acciones se realizaron al mismo tiempo y de manera uniforme en todas las provincias del país, a través de los gobiernos e instituciones estatales locales.

FIGURA 2. Acciones preventivas y terapéuticas adoptadas, desde la pesquisa hasta la recuperación de los casos confirmados con COVID-19, Cuba, 2020a

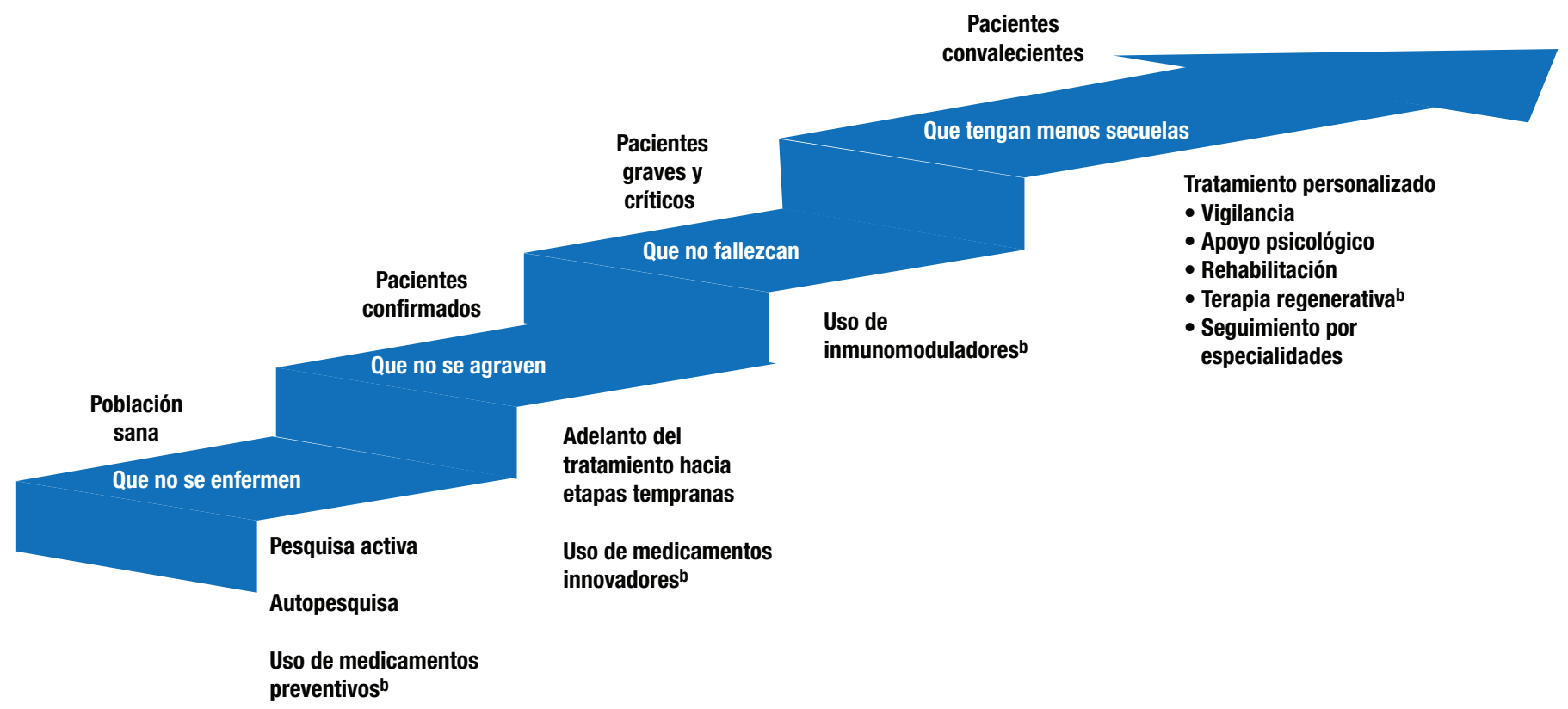

Fuente: Elaborado por la Dirección de Ciencia y Tecnología. Ministerio de Salud Pública. Tomado de: Presentación del Grupo Temporal de trabajo al Gobierno, 8 de octubre del 2020.

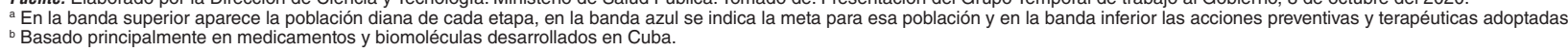


Con posterioridad, en dependencia de la evolución de la epidemia, esas acciones se fueron "desescalando" gradual y casuísticamente por territorio. El Grupo Temporal Nacional ha sido el encargado de aprobar esos cambios, siempre siguiendo criterios establecidos, iguales para todas las provincias, lo que es muestra de la equidad en el manejo de la epidemia por parte del gobierno central y la dirección política del país.

Todo lo anterior se ha visto reflejado en el índice de rigor de Oxford, una herramienta desarrollada por esa universidad -denominada en inglés Oxford Stringency Index - para valorar el grado de severidad o restricción de la respuesta de los gobiernos a la COVID-19 (31). Como se observa en la figura 3, las medidas que se fueron aplicando en Cuba de acuerdo con el comportamiento epidemiológico de la enfermedad se mantuvieron durante un mes después que se verificó el descenso en el número de casos en el mes de mayo; en ese período se mantuvo la máxima calificación de la escala. Posteriormente, se fueron suavizando lentamente las medidas, de manera diferenciada de acuerdo con la situación específica de cada territorio. Una vez detectado un incremento en la transmisión a principios de agosto, se procedió al reforzamiento de las medidas.

La evolución heterogénea de la epidemia en las provincias está relacionada, sobre todo, con factores que condicionan la transmisión del virus, como el nivel de urbanización, la densidad poblacional, y la mayor o menor movilidad en cada territorio, y no se debe a que se haya dado mayor prioridad a un territorio que a otro. Eso explica que se haya aplicado el "desescalado" — incluso algunos "reescalados" — de las medidas de manera diferente en la capital (y provincias aledañas) con respecto al resto del país.

Se debe subrayar que la tasa de letalidad registrada en Cuba es similar en los tres estratos identificados (bajo: 2,73; medio: $1,84$ y alto: 2,$01 ; p=0,80)$, lo que refleja, además de la calidad de los protocolos de tratamiento utilizados, que su aplicación ha sido la misma en todos los territorios del país.

Para lograr la sostenibilidad y mantener la equidad en el control y el tratamiento de la COVID-19 se requirió -y requiere- dotar a toda la red del SNS con insumos para el diagnóstico por PCR en tiempo real, medicamentos, equipamiento y medios de protección, entre otros recursos. El enfrentamiento a la pandemia ocurre en un momento en que se ha recrudecido fuertemente el bloqueo económico y financiero a que Cuba está sometida por parte del Gobierno de los Estados Unidos de América, que impide la entrada de recursos financieros al país y obstruye la importación de medicamentos y medios necesarios para combatir la pandemia, lo que impone un enorme reto adicional que ha sido necesario vencer para poder mantener las condiciones de equidad ante el grave escenario epidemiológico y asistencial que se vive y para enfrentar la pandemia (17).

De acuerdo con el comportamiento de la COVID-19 en el país, después de alcanzarse el pico de transmisión a mediados de abril —con una tasa de incidencia de 6,49 por 100000 habitantes- se logró el control temporal de la enfermedad hasta finales de julio. A partir de ese momento, comenzó un ascenso en el número de casos confirmados hasta llegar a la tasa máxima de 7,43 por 100000 habitantes en septiembre. El posterior descenso de la tasa de incidencia y el control de la transmisión son evidencia de la capacidad del SNS cubano para soportar lo que viene en el futuro: la persistencia de la enfermedad con la ocurrencia de rebrotes, o lo que es lo mismo, un período en el que debemos aprender a convivir con la enfermedad y enfrentar retos relacionados con el control sanitario internacional, el aislamiento de los contactos en el sistema de atención primaria, y la obtención y la aplicación a escala poblacional de una vacuna. En el momento de publicar este artículo, en Cuba se desarrollaban varios candidatos vacunales, de los cuales dos ya se encontraban en estudios clínicos en humanos.

FIGURA 3. Tasa de incidencia de casos confirmados de COVID-19 e índice de rigor de Oxford ${ }^{\text {, }}$ Cuba, 11 de marzo-30 de septiembre del 2020

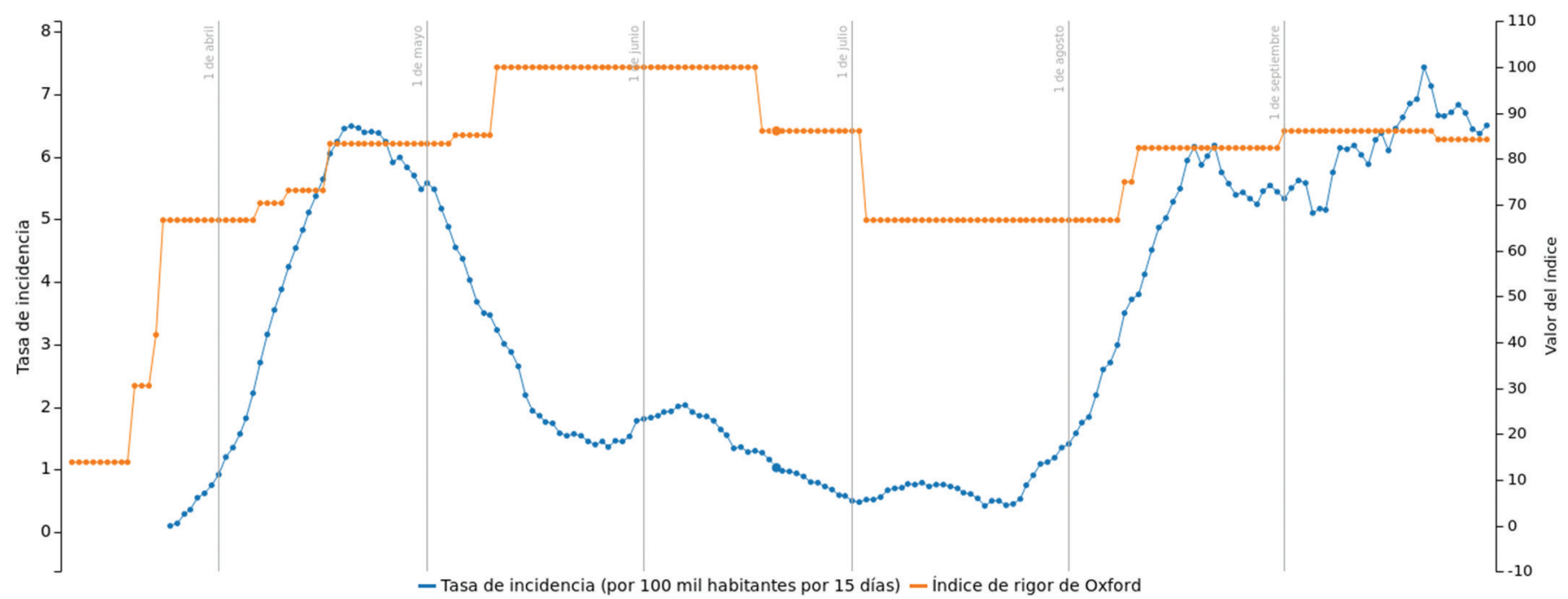

Fuente: Elaborado por los autores a partir de datos tomados de: https:Itcovid19cubadata.github.iof\#cuba

a El índice de rigor de Oxford (Oxford Stringency Index) valora el grado de severidad o restricción de la respuesta de los gobiernos a la COVID-19 (31) 
CUADRO 2. Lecciones aprendidas durante el control y el manejo de la pandemia por la COVID-19 en Cuba, 2020

\begin{tabular}{|c|c|c|}
\hline Dimensiones & Dificultades & Acciones \\
\hline Preparación & $\begin{array}{l}\text { Extensión de la epidemia por el } \\
\text { SARS-CoV-2 en el mundo, según lo } \\
\text { notificado por la Organización Mundial } \\
\text { de la Salud }\end{array}$ & $\begin{array}{l}\text { - Voluntad política del gobierno en el enfrentamiento y el control de la enfermedad } \\
\text { - Elaboración del Plan para la Prevención y Control del Coronavirus } \\
\text { - Creación del Grupo Temporal de Trabajo Intersectorial para Enfrentar la COVID-19 bajo el principio de la } \\
\text { intersectorialidad de las acciones } \\
\text { - Elaboración de políticas de comunicación, que incluyen el uso de los medios masivos de difusión y las } \\
\text { - } \text { - Ajustes sociales en la asa la comunicación a la población } \\
\text { - Preparación de los recursos humanos }\end{array}$ \\
\hline Pesquisa activa & $\begin{array}{l}\text { Gran transmisibilidad del virus } \\
\text { Desconocimiento de la seroprevalencia } \\
\text { en la población }\end{array}$ & $\begin{array}{l}\text { - Movilización del sistema de atención primaria de salud y su fortalecimiento con estudiantes de medicina } \\
\text { - Rastreo para la detección temprana y el aislamiento de los casos positivos y sus contactos } \\
\text { - Identificación de formas graves de la enfermedad y de grupos vulnerables con enfermedades } \\
\text { preexistentes }\end{array}$ \\
\hline $\begin{array}{l}\text { Pruebas } \\
\text { diagnósticas }\end{array}$ & $\begin{array}{l}\text { Prueba diagnóstica para la detección del } \\
\text { SARS-CoV-2 nueva y costosa }\end{array}$ & $\begin{array}{l}\text { - Implementación de una red de laboratorios de biología molecular para aplicar el diagnóstico molecular } \\
\text { mediante la reacción en cadena de la polimerasa (PCR) en tiempo real }\end{array}$ \\
\hline $\begin{array}{l}\text { Intervenciones } \\
\text { terapéuticas }\end{array}$ & $\begin{array}{l}\text { Necesidad de tratamientos específicos } \\
\text { y precisos }\end{array}$ & $\begin{array}{l}\text { - Creación de modelos y protocolos preventivos y terapéuticos } \\
\text { - Desarrollo en el país de los medicamentos de primera línea }\end{array}$ \\
\hline Letalidad & $\begin{array}{l}\text { Evitar que las personas enfermen, } \\
\text { sufran complicaciones o mueran }\end{array}$ & $\begin{array}{l}\text { - Establecimiento de acciones preventivas y terapéuticas desde la pesquisa, a fin de lograr que la } \\
\text { población sana no enferme, si se enferma no se agrave y si se agrava no fallezca, y que tenga una } \\
\text { convalecencia con menos secuelas } \\
\text { - Establecimiento de normas de conducta y terapia, según un protocolo que indica qué hacer en cada } \\
\text { momento de la evolución de la enfermedad } \\
\text { - Participación de la industria biomédica y biotecnológica cubana en el desarrollo y la aplicación de } \\
\text { fármacos innovadores específicos, equipos y vacunas contra la enfermedad }\end{array}$ \\
\hline Equidad & $\begin{array}{l}\text { Necesidad de que los servicios de salud } \\
\text { sean equitativos y no colapsen }\end{array}$ & $\begin{array}{l}\text { - Mantenimiento de todos los servicios, desde la prevención y el diagnóstico hasta el aislamiento, la } \\
\text { hospitalización y la atención en cuidados intensivos gratuitos y universales } \\
\text { - Proyección intersectorial y comunitaria de todas las acciones } \\
\text { - Reordenamiento e incremento de las capacidades en los servicios de salud } \\
\text { - Pruebas diagnósticas libres de costo a toda la población en riesgo } \\
\text { - Control y seguimiento activo de los casos confirmados y los sospechosos }\end{array}$ \\
\hline
\end{tabular}

Fuente: Elaborado por los autores.

La experiencia vivida en Cuba ha permitido encontrar soluciones a los problemas y obstáculos que han ido apareciendo. Este aprendizaje a partir de las dificultades generó un conjunto de acciones que permitieron el control de la pandemia en Cuba y constituyen lecciones aprendidas que pueden ser útiles en otros contextos similares (cuadro 2).

\section{CONCLUSIONES}

La organización del SNS cubano y la eficacia de su respuesta en el enfrentamiento de la COVID-19 han respetado la premisa de garantizar la equidad en los sistemas y servicios de salud, de manera accesible y gratuita, a todos sus ciudadanos. Debido a que esas condiciones ya se cumplían antes de que la pandemia llegara a Cuba, fue posible lograr los resultados positivos en el enfrentamiento a la COVID-19 en el país desde los primeros momentos de la pandemia. Esta experiencia, además, ha aportado un grupo de lecciones que enriquecieron la estrategia de enfrentamiento a situaciones extremas en Cuba, cuyos elementos clave son: la preparación de un plan nacional único, la utilización de estrategias particulares para la pesquisa, el diagnóstico y el rastreo de casos, la implementación de un protocolo terapéutico y de manejo de pacientes confirmados único, y la respuesta gubernamental e intersectorial. Estos elementos han permitido controlar la enfermedad en Cuba manteniendo la equidad en la salud.

Contribución de los autores. PMB (https://orcid.org/ 0000-0002-5350-657X), LSV (https:/ / orcid.org/0000-0001-77471052), MVL (https://orcid.org/0000-0002-0293-5999), ASJ (https://orcid.org/0000-0002-2231-0822) y RMO (https:// orcid.org/0000-0001-9251-7127) concibieron el estudio original. LSL (https: / / orcid.org/0000-0002-9399-7238) y YAC (https:/ / orcid.org/0000-0002-2345-1387) recolectaron los datos; LSV, YAC, MVL, ASJ, PMB analizaron los datos e interpretaron los resultados. PMB, LSV, MVL, CVO (https://orcid.org/00000003-0276-6264), IAS (https://orcid.org/0000-0003-2296-5041) escribieron el manuscrito y realizaron la revisión bibliográfica. Todos los autores revisaron y aprobaron la versión final.

Agradecimientos. Los autores agradecen al editor y a los revisores los comentarios realizados, que permitieron mejorar el manuscrito. A Daniel González y Lisset López por la información sobre la vulnerabilidad, el riesgo y el protocolo de manejo de casos en pacientes adultos y pediátricos, respectivamente. 
Conflictos de intereses. Los autores declaran no tener conflictos de intereses, aunque han participado en el desarrollo de las estrategias analizadas en el artículo.

Financiación. Este estudio no ha recibido financiación.
Declaración. Las opiniones expresadas en este artículo son únicamente responsabilidad de los autores y no reflejan necesariamente los criterios ni la política de la Revista Panamericana de Salud Pública / Pan American Journal of Public Health y/o la Organización Panamericana de la Salud.

\section{REFERENCIAS}

1. Sánchez P. Ética nicomáquea, ética eudemia. Madrid: Gredos; 1988 [citado el 18 de julio del 2020]. Disponible en: http://www .posgrado.unam.mx/filosofia/pdfs / Aristoteles Etica-a-Nicomaco -Etica-Eudemia-Gredos.pdf

2. Equidad. Significados.com [Internet]; 2020 [citado el 18 de julio del 2020]. Disponible en: https://www.significados.com/equidad/

3. España, Ministerio de Sanidad, Consumo y Bienestar Social. Equidad en salud y desigualdades sociales en salud [Internet]. Madrid: MSCBS; 2020 [citado el 18 de julio del 2020]. Disponible en: https:/ / www.mscbs.gob.es/profesionales/saludPublica/prevPromocion/ promocion/desigualdadSalud/EquidadSaludyDSS.htm

4. República de Cuba, Ministerio de Salud Pública. Parte de cierre del día $1{ }^{\circ}$ de octubre a las 12 de la noche. La Habana: MINSAP; 2020 [citado el 26 de octubre del 2020]. Disponible en: https:/ / salud.msp. gob.cu/parte-de-cierre-del-dia-1-de-octubre-a-las-12-de-la-noche/

5. Shamasunder S, Holmes SM, Goronga T, Carrasco H, Katz E, Frankfurter R, et al. COVID-19 reveals weak health systems by design: Why we must re-make global health in this historic moment. Glob Public Health. 2020;15(7):1083-9 [citado el 26 de octubre del 2020]. Disponible en: https://www.tandfonline.com/doi/full/10.1080/1 7441692.2020.1760915

6. Organización Panamericana de la Salud. Promoción de la equidad en la salud, la igualdad étnica y de género y los derechos humanos en la respuesta a la COVID-19: consideraciones clave. Washington, DC: OPS; 2020 [citado el 3 de agosto del 2020]. (OPS/EGC/ LEG/COVID-19-0001). Disponible en: https://iris.paho.org/ handle/10665.2/52075

7. Zabala MC, Fundora G. Retos para la equidad social en el proceso de actualización del modelo económico cubano. Perf Cult Cubana. 2019;25:231-3 [citado el 18 de julio del 2020]. Disponible en: http:/ / www.perfiles.cult.cu/articulos /9\%20Perfiles-num25-Zabala_M-d-C.pdf

8. Constitución de la República de Cuba. Granma. 2019 abril 9 [citado el 18 de julio del 2020]. Disponible en: http://www.granma.cu/ file/pdf/gaceta/Nueva\%20Constituci\%C3\%B3n\%20240\%20KB-1. pdf

9. Morales R, Mas P, Castell-Florit P, Arocha C, Valdivia NC, Druyet D, et al. Transformaciones en el sistema de salud en Cuba y estrategias actuales para su consolidación y sostenibilidad. Rev Panam Salud Publica. 2018;42:e25 [citado el 18 de julio del 2020]. Disponible en: https://doi.org/10.26633/RPSP.2018.25

10. Di Fabio HL, Gofin R, Gofin J. Análisis del sistema de salud cubano y del modelo de atención primaria orientada a la comunidad. Rev Cubana Salud Publica. 2020;46(2):e2193 [citado el 18 de julio del 2020]. Disponible en: http://www.revsaludpublica.sld.cu/index. $\mathrm{php} / \mathrm{spu} /$ article/view/2193/

11. Pérez B. La equidad en los servicios de salud. Rev Cubana Salud Publica. 2007;33(3) [citado el 4 de agosto del 2020]. Disponible en: http://scielo.sld.cu/pdf/rcsp/v33n3/spu07307.pdf

12. Castell-Florit P, Acevedo Martínez M, Vidal Ledo MJ. La intersectorialidad en Cuba es una fortaleza para el enfrentamiento a la COVID-19. Infodir. 2020;33:e836 [citado el 12 de mayo del 2020]. Disponible en: http://www.revinfodir.sld.cu/index.php/infodir/ article/view/836/

13. Ministerio de Salud Pública. Anuario Estadístico de Salud, 2019. La Habana: Dirección de Registros Médicos y Estadísticas de Salud; 2020 [citado el 12 de mayo del 2020]. Disponible en: https://files. sld.cu/bvscuba / files /2020/05/Anuario-Electr\%c3\%b3nico-Espa\%c3\%b1ol-2019-ed-2020.pdf

14. Corral A, Pría MC. Diseño de un índice de condiciones de vida y clasificación del territorio nacional. Rev Med Gen Integral. 2017;31(3):323-32 [citado el 4 de agosto del 2020]. Disponible en: http://scielo.sld.cu/pdf/v31n3/mgi073015.pdf
15. Whitehead M. Los conceptos y principios de la equidad en la salud. Washington DC: Organización Panamericana de la Salud; 1991 [citado el 4 de agosto del 2020]. Disponible en: http://onis.salud. gob.mx/site4/somos/docs/taller analisis datos bibliografia_27.pdf

16. República de Cuba, Ministerio de Salud Pública. Plan de prevención y control de la COVID-19, estrategia para estar debida y oportunamente preparados. La Habana: MINSAP; 2020 [citado el 4 de agosto del 2020]. Disponible en: https://www.presidencia.gob.cu/ es/noticias/plan-de-prevencion-y-control-del-covid-19-estrategiapara-estar-debida-y-oportunamente-preparados /

17. Díaz-Canel M, Núñez-Jover J. Gestión gubernamental y ciencia cubana en el enfrentamiento a la COVID-19. An Acad Cienc Cuba. 2020;10(2) [citado el 22 de junio del 2020]. Disponible en: http:/ / www.revistaccuba.cu/index.php/revacc/article/view / $881 / 886$

18. República de Cuba, Ministerio de Salud Pública. Plan de Prevención y Control para el Enfrentamiento a la COVID-19. La Habana: MINSAP; 2020.

19. Más P, Vidal M, Baldoquin W, Seuc AH, Guinovart R, Pérez N, et al. Organización de la investigación epidemiológica para la lucha antiepidémica contra la COVID-19 en Cuba. Infodir. 2020 [citado el 12 de mayo del 2020];33:e831. Disponible en: http://revinfodir.sld. $\mathrm{cu} /$ index.php/infodir/article/view/831/ 1103

20. Cuba informa 40 medidas para el enfrentamiento al nuevo coronavirus COVID-19. Granma. 2020 marzo 24 [citado el 25 de marzo del 2020]. Disponible en: http://www.granma.cu/cuba-covid-19/2020 -03-24/el-primer-secretario-del-pcc-y-el-presidente-activaron-los -consejos-de-defensa-en-el-pais-24-03-2020-01-03-10

21. Reyes S, Fernández J. ¿Se puede evaluar la respuesta de un gobierno ante la COVID-19? CubaData. 2020 [citado el 5 de mayo del 2020]. Disponible en: http://www.acn.cu/cuba/64175-se-puede-evaluarla-respuesta-de-un-gobierno-ante-la-covid-19

22. República de Cuba, Ministerio de Salud Pública. Coronavirus en Cuba. Información Oficial del MINSAP. La Habana: MINSAP; 2020 [citado el 16 de agosto del 2020]. Disponible en: https:/ / salud.msp. gob.cu/

23. República de Cuba, Ministerio de Salud Pública. Protocolo de actuación nacional para la COVID-19. La Habana; 2020 [citado el 26 de agosto del 2020]. Disponible en: http://files.sld.cu/ editorhome/ files/2020/08/version-5-del-protocolo-para-publicar13-de-agosto-2020.pdf

24. Galván-García E, Mas Bermejo P. COVID-19 in Cuba: Assessing the national response. MEDICC Rev. 2020;22(4) [citado el 30 de octubre del 2020]. Disponible en: https://mediccreview.org/covid -19-in-cuba-assessing-the-national-response /

25. López L, Noda A, Castro B, Cruz SM, Causa N, Cabrera L, et al. Caracterización clínico epidemiológica de 183 niños cubanos con infección por SARs-COV2. Rev Cubana Pediatr. 2020;92 Suppl:e1256 [citado el 2 de octubre del 2020]. Disponible en:http://www.revpediatria .sld.cu/index.php/ped/article/view/1256

26. Saavedra D, Fuertes SA, Suárez GM, González A, Lorenzo-Luaces P, García B, et al. Biomodulina T partially restores immunosenescentCD4 and CD8 T-cell compartments in the elderly. Exp Gerontol. 2019;124 [citado el 2 de octubre del 2020]. Disponible en: https: / / www.science direct.com/science/article/abs/pii/S0531556518305850

27. Saborit A. Presencia de la medicina natural y tradicional en la batalla contra la COVID-19. Rev 16 Abril. 2020;59(277):e978 [citado el 5 de mayo del 2020]. Disponible en: http://www.rev16deabril.sld. cu/index.php/16_04/article/view/978

28. Bello-Rivero I, García-Vega Y, Ducan-Roberts Y, Vázquez-Blomquists D, Santana-Milián H, Besada-Pérez V, et al. HeberFERON, a new formulation of IFNs with improved pharmacodynamics: Perspective for cancer treatment. Semin Oncol. 2018;45:27-33 [citado el 5 
de mayo del 2020]. Disponible en: https: / /www.sciencedirect.com/ science/article/abs/pii/S0093775418300915

29. Hernández P, Moreno E, Aira LE, Rodríguez PC. Therapeutic targeting of CD6 in autoimmune diseases: A review of Cuban clinical studies with the antibodies IOR-T1 and Itolizumab. Curr Drug Targets. 2016;17(6):666-77 [citado el 2 de octubre del 2020]. Disponible en: https:/ / europepmc.org/article/med/26844560

30. Venegas-Rodríguez R, Santana-Sánchez R, Peña-Ruiz $R$, Bequet-Romero M, Hernández-Cedeño $M$, Santiesteban-Licea B, et al. CIGB-258 immunomodulatory peptide: a novel promising treatment for critical and severe COVID-19 patients. MedRxiv Reprints; 2020. doi: https://www.medrxiv.org/content/ 10.1101/2020.05.27.20110601v1.full.pdf
31. Hale T, Webster A, Petherick A, Phillips T, Kira B. Oxford COVID-19 government response tracker. Oxford, UK: University of Oxford, Blavatnik School of Government; 2020 [citado el 5 de mayo del 2020]. Disponible en: https://www.bsg.ox.ac.uk/research/ research-projects/coronavirus-government-response-tracker

Manuscrito recibido el 24 de agosto del 2020. Aceptado para publicación, tras revisión, el 19 de octubre del 2020

\section{Equity and the Cuban National Health System's response to COVID-19}

\section{ABSTRACT}

Keywords
Cuba's National Health System has managed to guarantee an effective and equitable response to COVID-19. Universal and free health coverage, based on primary care, follows the principle of equity, and the greatest resources are allocated to areas of the lowest socioeconomic stratum (which concentrates the higher health risks), followed by those of medium and high strata, in that order. This allowed for similar mortality rates in the three strata, and Cuban national mortality rate was one of the lowest in the Region of the Americas. Before the first case was identified in Cuba, a Plan for Coronavirus Prevention and Control was elaborated with multisectoral participation, and when the first case was confirmed the Temporary Working Group to Fight COVID-19 was created as an advisory body of the government. The actions to face the pandemic began with preventive measures in the community, continued in the isolation centers and ended again in the community with actions of surveillance and follow up of recovered patients. Following the principle of territoriality, laboratories of molecular diagnosis were created in the provinces that did not have it. Free medical care and treatment; the preparation of a single national intersectoral government plan; the use of particular strategies for research, diagnosis and case tracing; and the implementation of a universal protocol for disease prevention and treatment of confirmed cases allowed to control the disease with a perspective of equity in health.

Coronavirus infections; health equity; universal health coverage; primary health care; Cuba. 


\section{Equidade e resposta do Sistema Nacional de Saúde de Cuba à pandemia de COVID-19}

RESUMO O Sistema Nacional de Saúde de Cuba tem assegurado uma resposta eficaz e com equidade ao enfrentar a pandemia de COVID-19. A cobertura de saúde universal e gratuita baseada na atenção primária se pauta no princípio da equidade. Mais recursos são destinados às áreas de nível socioeconômico mais baixo que concentram risco de saúde maior e a seguir, nesta ordem, às áreas de nível socioeconômico médio e alto. Assim, a taxas de letalidade tem sido semelhante nos três níveis e a taxa nacional é uma das mais baixas da Região. Antes de o primeiro caso de COVID-19 ter sido detectado em Cuba, preparou-se o Plano para prevenção e controle do coronavírus com participação multissetorial. Quando o primeiro caso da doença foi confirmado, instituiu-se o Grupo de trabalho temporário para combater a COVID-19 como um órgão assessor do governo. As ações de combate à pandemia começam na comunidade com medidas preventivas, prosseguem nos centros de isolamento e retornam à comunidade com medidas de vigilância sanitária e o acompanhamento dos pacientes recuperados. E, seguindo o princípio de territorialidade, laboratórios de diagnóstico molecular foram instituídos nas províncias onde eles inexistiam. A atenção médica, o tratamento gratuito, a preparação de um plano de governo único intersetorial nacional, o emprego de estratégias próprias para pesquisa, diagnóstico e rastreio de casos e a implementação de um protocolo universal para prevenção da doença e tratamento dos casos confirmados possibilitaram controlar a doença de uma perspectiva de equidade em saúde.

Palavras-chave

Infecções por coronavirus; equidade em saúde; cobertura universal de saúde; atenção primária à saúde; Cuba. 